\title{
Induction of autophagy by the MG-132 proteasome inhibitor is associated with endoplasmic reticulum stress in MCF-7 cells
}

\author{
WENHUA BAO ${ }^{1}$, YIQI GU ${ }^{1}$, LA TA $^{2}$, KEREN WANG ${ }^{1}$ and ZHELI XU ${ }^{1}$ \\ ${ }^{1}$ Department of Breast Surgery, China-Japan Union Hospital of Jilin University, Changchun, Jilin 130033; \\ ${ }^{2}$ Department of Surgery, The Affiliated Hospital of Inner Mongolia Medical University, \\ Hohhot, Inner Mongolia 010050, P.R. China
}

Received December 19, 2014; Accepted October 5, 2015

DOI: $10.3892 / \mathrm{mmr} .2015 .4599$

\begin{abstract}
The aim of the present study was to investigate whether endoplasmic reticulum (ER) stress is involved in MG-132-induced autophagy, and to determine the effects of the inhibition of autophagy and ER stress on cell viability following MG-132 treatment. The proteasome inhibitor, MG-132, was used to induce autophagy in MCF-7 cells, and 3-methyladenine (3-MA) and salubrinal were used to inhibit autophagy and ER stress, respectively. An MTT assay was used to analyze cell viability. Apoptosis and the cell cycle were analyzed using flow cytometry. The expression levels of apoptosis- and ER stress-associated genes were investigated using western blot and reverse transcription-quantitative polymerase chain reaction analyses. MG-132 inhibited cell proliferation, and induced apoptosis and cell cycle arrest at the $G_{2}$ phase of the cell cycle. Notably, MG-132 increased the autophagy-associated conversion of microtubule-associated protein 1 light chain 3 (LC3)-I to LC3-II, which was partially attenuated by the ER stress inhibitor, salubrinal. In addition, MG-132 inhibited the protein expression of the anti-apoptotic protein, B-cell lymphoma (Bcl)-2, whereas the expression levels of Bcl-2-associated X protein and caspase-3 were upregulated. These effects were enhanced by co-treatment with either 3-MA or salubrinal. Furthermore, the mRNA and protein levels of the ER stress-associated genes, glucose-regulated protein 78, growth arrest and DNA damage induced gene-153, and caspase-12, were upregulated by MG132, and these levels were significantly inhibited by co-treatment of the cells with salubrinal. Taken together, the results of the present study indicated that the induction of autophagy by the proteasome inhibitor was associated with ER stress in the MCF-7 cells, and that the inhibition of autophagy or ER stress enhanced
\end{abstract}

Correspondence to: Dr Zheli Xu, Department of Breast Surgery, China-Japan Union Hospital of Jilin University, 126 Xian Tai Road, Changchun, Jilin 130033, P.R. China

E-mail:wenhuabao18@gmail.com

Key words: proteasome inhibitors, autophagy, endoplasmic reticulum stress, cell death
MG-132-induced apoptosis. These findings suggest the potential application of inhibitors of ER stress and autophagy, in combination with proteasomal inhibitors, for the development of combinatorial targeted cancer therapy.

\section{Introduction}

The ubiquitin-proteasome (UPP) and autophagy pathways are the two major pathways involved in the degradation of intracellular proteins in eukaryotic cells. The UPP pathway predominantly degrades short half-life proteins, whereas autophagy degrades long half-life proteins and organelles (1). The proteasome pathway is key in maintaining the homeostasis of intracellular protein metabolism, thereby regulating cell cycle progression, cell differentiation and DNA damage repair (2). Targeting the proteasome pathway is a promising strategy for cancer therapy, as evidenced by the effects of several proteasome inhibitors in preclinical and clinical trials (3-5). However, clinical trials have demonstrated that developing resistance to proteasome-targeting drugs is a significant problem (6).

Autophagy degrades proteins and organelles via the lysosome, which enables cells to digest their intrinsic components to obtain the energy and nutrients required to survive in adverse microenvironments (7). Under normal physiological conditions, autophagy is limited to a base level, however, under stressful conditions, autophagy is enhanced (8). Autophagy can be regarded as a 'double-edged sword'; sustained and excessive activation of autophagy may lead to autophagic cell death, while moderate induction of autophagy promotes cell survival (9). Accumulating evidence has demonstrated that autophagy affects the sensitivity of tumor cells to radiotherapy, chemotherapy and immunotherapy in several types of cancer, including prostate and colon cancer, glioma and melanoma (10-14). It has been previously reported that inhibiting autophagy enhances the sensitivity of tumor cells to radiotherapy $(15,16)$. In addition, the activation of autophagy attenuates the cytotoxicity of anti-HER 2 monoclonal antibody in breast cancer cells (17). Furthermore, autophagy has been found to significantly improve the tolerance of hepatoma cells to chemotherapy (18).

Previous studies have demonstrated that proteasome inhibitors not only induce apoptosis, but they also activate 
autophagy in tumor cells (9). In our previous study, inhibition of the proteasome induced apoptosis and autophagy (9). These data indicated that autophagy also contributed to the resistance of cancer cells to proteasome inhibitors. However, the underlying mechanism remains to be fully elucidated.

The endoplasmic reticulum (ER) synthesizes proteins and stores calcium, in addition to detecting and responding to alterations in the microenvironment (19). Conditions of stress result in ER stress, which in turn triggers the unfolded protein response (20). ER chaperones mediate ER associated protein degradation (ERAD) (21). ERAD detects and removes misfolded proteins in the ER through the UPP and autophagy-lysosomal pathways. Studies have demonstrated that abnormal protein aggregation within the ER can activate the protein kinase RNA-like endoplasmic reticulum kinase pathway and induce eukaryotic translation initiation factor $2 \alpha$ (eIF2 $\alpha$ ) phosphorylation, which promotes autophagy (22). Previous studies have shown that the treatment of cancer cells with proteasome inhibitors leads to autophagy accompanied by ER stress (23-26). Therefore, the present study hypothesized that ER stress may contribute to the induction of autophagy by proteasome inhibitors, and that the inhibition of ER stress or autophagy may sensitize cancer cells to proteasome-targeting drugs.

In the present study, MCF-7 human breast cancer cells were treated with the proteasome inhibitor, MG-132, in the presence or absence of the autophagy inhibitor, 3-methyladenine (3-MA), or the ER stress inhibitor, salubrinal. Subsequently, the effects of treatment on cell viability, apoptosis and the induction of autophagy were determined. The aim of the current study was to investigate the promoting role of autophagy inhibitor 3-MA and endoplasmic reticulum stress inhibitor salubrinal on the MCF-7 cell-growth inhibition effect of proteasome inhibitor MG-132, and to provide a theoretical basis for the future development of breast cancer treatments.

\section{Materials and methods}

Reagents. Gibco Dulbecco's modified Eagle's medium (DMEM) was purchased from Thermo Fisher Scientific, Inc. (Waltham, MA, USA); fetal bovine serum (FBS) was purchased from TBD Science (Hangzhou, China); Calbiochem MG-132 was obtained from EMD Millipore (San Diego, CA, USA) and was dissolved in phosphate-buffered saline (PBS) to a storage concentration of $20 \mu \mathrm{mol} / 1$. 3-MA was purchased from Sigma-Aldrich (St. Louis, MO, USA) and was dissolved in PBS to a storage concentration of $100 \mathrm{mmol} / \mathrm{l}$. Salubrinal was purchased from EMD Millipore and was dissolved in PBS to a storage concentration of $100 \mu \mathrm{mol} / \mathrm{l}$. The polyclonal rabbit anti-microtubule-associated protein 1 light chain 3 (LC3; cat. no. 4108) antibody, polyclonal rabbit anti-caspase-3 (cat. no. 9662) and polyclonal rabbit anti-caspase-12 (cat. no. 2202) antibodies were purchased from Cell Signaling Technology, Inc. (Danvers, MA, USA), and the monoclonal mouse anti-B cell lymphoma-2 (BCL-2; cat. no. ab692), monoclonal mouse anti-Bcl-2-associated X protein (BAX; cat. no. ab5714), monoclonal mouse anti-glucose-regulated protein 78 (Grp-78; ab151269) and monoclonal mouse anti-GADD153 (cat. no. ab11419) antibodies were purchased from Abcam (Cambridge, MA, USA). The Cell Cycle and Apoptosis
Analysis kits were obtained from Beyotime Institute of Biotechnology (cat. nos. C1052 and C1063; Shanghai, China).

Cell line and cell culture. Human MCF-7 breast cancer cells were obtained from the Gene Treatment Center of the China-Japan Union Hospital of Jilin University (Changchun, China). The MCF-7 cells were cultured in DMEM supplemented with $10 \% \mathrm{FBS}$, and were maintained at $37^{\circ} \mathrm{C}$ and $5 \% \mathrm{CO}_{2}$. Cells (80-90\% confluence) in the mid-log phase were used in the subsequent experiments.

MTT assay to determine cell viability. The MCF-7 cells were seeded onto 96-well plates at a concentration of $1 \times 10^{5}$ cells/well and cultured overnight at $37^{\circ} \mathrm{C}$. The cells were divided into three groups. The first group was treated with $2.5 \mu \mathrm{mol} / 1 \mathrm{MG}-132$; the second group was co-treated with $1.0 \mathrm{mmol} / \mathrm{l} 3-\mathrm{MA}$ and MG-132; and the third group was co-treated with $10 \mu \mathrm{mol} / 1$ salubrinal and MG-132. All groups were treated for 12,24 and $48 \mathrm{~h}$ at $37^{\circ} \mathrm{C}$. Subsequent to treatment, each group of cells was incubated with $5 \mathrm{mg} / \mathrm{ml} \mathrm{MTT}$ for $4 \mathrm{~h}$, followed by detection using an enzyme-labeling measuring instrument (Model 680; Bio-Rad Laboratories, Inc., Hercules, CA, USA) at $570 \mathrm{~nm}$. Each experiment was repeated three times in triplicate.

Detection of apoptosis and cell cycle. Annexin V-fluorescein isothiocyanate (FITC) and propidium iodide (PI) (Beyotime Institute of Biotechnology, Haimen, China) were used to evaluate the rates of apoptosis of the cells. Subsequent to washing twice with PBS and adjusting the cells to a density of $5 \times 10^{5}$ cells $/ \mathrm{ml}$, one group of MCF-7 cells were fixed in $70 \%$ ethanol at $4^{\circ} \mathrm{C}$ overnight, treated with $100 \mathrm{mg} / \mathrm{l}$ Rase (Beyotime Institute of Biotechnology) at $37^{\circ} \mathrm{C}$ for $30 \mathrm{~min}$ and stained with $50 \mathrm{mg} / \mathrm{l} \mathrm{PI}$ at $4^{\circ} \mathrm{C}$ for $30 \mathrm{~min}$. Another group was stained with $150 \mathrm{mg} / \mathrm{l} \mathrm{FITC}$ at $20-25^{\circ} \mathrm{C}$ for $10 \mathrm{~min}$ and with $50 \mathrm{mg} / \mathrm{l} \mathrm{PI}$ at $4^{\circ} \mathrm{C}$ for $30 \mathrm{~min}$. Following starvation overnight at $37^{\circ} \mathrm{C}$ in serum-free DMEM, the MCF- 7 cells $\left(1 \times 10^{5}\right.$ cells $\left./ \mathrm{ml}\right)$ were either treated with $2.5 \mu \mathrm{mol} / 1 \mathrm{MG}-132$ or were co-treated with $1.0 \mathrm{mmol} / 13-\mathrm{MA}$ or $10 \mu \mathrm{mol} / 1$ salubrinal for $48 \mathrm{~h}$ at $37^{\circ} \mathrm{C}$. Following treatment, the attached and floating cells were harvested with $0.25 \%$ trypsin (Amresco LLC, Solon, $\mathrm{OH}$, USA), washed twice with PBS and adjusted to a density of $5 \times 10^{5}$ cells $/ \mathrm{ml}$. Flow cytometric analysis was then performed using the FACScan flow cytometer (BD Biosciences, San Jose, CA, USA), according to the manufacturer's protocol of the Cell Cycle and Apoptosis Analysis kit (Beyotime Institute of Biotechnology).

Western blotting. Protein was extracted from cells with lysis buffer (Beijing Chemicals Company Limited, Beijing, China) containing $1 \%$ Nonidet $\mathrm{P}-40,150 \mathrm{mM} \mathrm{NaCl}$, $50 \mathrm{mM}$ Tris- $\mathrm{HCl}$ (pH 7.5), $1 \mathrm{mM} \mathrm{NaF}, 1 \mathrm{mM}$ phenylmethylsulfonyl fluoride, $4 \mathrm{mg} / \mathrm{ml}$ leupeptin and $1 \mathrm{mg} / \mathrm{ml}$ aprotinin for $30 \mathrm{~min}$. Proteins were quantified with Coomassie Blue staining assay using the Bradford Protein Assay kit (Beyotime Institute of Biotechnology). Proteins (50 $\mu \mathrm{g} ; 5 \mu \mathrm{g} / \mu \mathrm{l})$ were resolved on a $12 \%$ sodium dodecyl sulfate-polyacrylamide gel (Beijing Chemicals Company Limited) and transferred to polyvinylidene difluoride membranes (Beyotime Institute of Biotechnology) followed by blocking with $5 \%$ fat free dry 
milk in Tris-buffered saline with Tween 20 (TBST; Beijing Chemicals Company Limited), containing $20 \mathrm{mM}$ Tris- $\mathrm{HCl}$ (pH 7.6), $150 \mathrm{mM} \mathrm{NaCl}$ and $0.02 \%$ Tween 20 . The membranes were then incubated with the following primary antibodies in TBST containing $0.1 \%$ Tween 20 and $1 \%$ fat-free milk, at $4^{\circ} \mathrm{C}$ overnight: LC3 (1:2,000); BCL-2 (1:3,000); BAX (1:500); polyclonal rabbit caspase-3 (1:1,000; cat. no. 9662; Cell Signaling Technology, Inc.); caspase-12 (1:1,000); Grp-78 $(1: 2,000)$. The membranes were then washed four times in TBST and incubated at $20-25^{\circ} \mathrm{C}$ for 30 min with horseradish peroxidase-conjugated secondary antibody $(1: 2,000$; Bio-Rad Laboratories, Inc.). Signals were developed using an ECL-Plus kit (Beyotime Institute of Biotechnology). Protein expression levels were quantified using ImageJ software (version 1.48; National Institutes of Health, Bethesda, MD, USA)

$R N A$ extraction and reverse transcription-quantitative polymerase chain reaction ( $R T-q P C R)$. The MCF- 7 cells were plated onto a 6-well plate at a concentration of $2 \times 10^{5}$ cells/well. Following $24 \mathrm{~h}$ incubation, the cells were treated with MG-132 $(2.5 \mu \mathrm{mol} / \mathrm{l})$ and co-treated with salubrinal (10 and $20 \mu \mathrm{mol} / \mathrm{l})$ for an additional $24 \mathrm{~h}$. Total RNA was extracted using Invitrogen TRIzol reagent (Thermo Fisher Scientific, Inc.), according to the manufacturer's protocol. Total RNA $(1 \mu \mathrm{g})$ was reverse transcribed using a Reverse Transcription system (Select Cycler II Gradient PCR Instrument; Takara Biotechnology, Co., Ltd., Dalian, China). The single-stranded cDNA was amplified by qPCR with the BeyoRT First Strand cDNA synthesis kit (RNase H minus; D7233; Beyotime Institute of Biotechnology) using primer pairs specific for GRP-78, growth arrest and DNA damage induced gene-153 (GADD153), caspase-12 and GAPDH. The reaction mixture was in a total volume of $50 \mu 1$ and contained cDNA $(0.5 \mu \mathrm{g})$, buffer $(5 \mu \mathrm{l})$, primers $(2 \mu \mathrm{l}$; Genewiz Biological Technology Co., Ltd., Beijing, China), dNTP mixture $(8 \mu \mathrm{l})$, Taq $(0.5 \mu \mathrm{l})$ and $\mathrm{ddH}_{2} \mathrm{O}$ (from the BeyoRT First Strand cDNA synthesis kit). Cycling was conducted using a PX2 Thermal Cycler (Thermo Fisher Scientific, Inc.) and the qPCR conditions were as follows: $95^{\circ} \mathrm{C}$ for $5 \mathrm{~min}$, followed by $95^{\circ} \mathrm{C}$ for $40 \mathrm{sec}, 55^{\circ} \mathrm{C}$ for $40 \mathrm{sec}$ and $72^{\circ} \mathrm{C}$ for $1 \mathrm{~min}$ for 25 cycles, and $72^{\circ} \mathrm{C}$ for $10 \mathrm{~min}$. The primers (GENEWIZ Biological Technology Company Limited, Jiangsu, China) used in the present study were as follows: Grp-78, forward 5'-GCAGCAGGACATCAAGTTCT-3' and reverse 5'-CGC TGGTCAAAGTCTTCTCC-3'; caspase-12, forward 5'-AAT CTGTGGGACCAAGCAAC-3' and reverse 5'-GAGCCT TTGTAACAGCATCA-3'; and GADD153, forward 5'-AAT GCTTGCTCTGATAGGCG-3' and reverse 5'-CTGGAATCT GGAGAGTGAGG-3'. The qPCR products were analyzed using a $1 \%$ agarose gel (Beijing Chemicals Company Limited, Beijing, China).

Statistical analysis. Data were analyzed using SPSS software, version 17.0 (SPSS, Inc., Chicago, IL, USA). Experiments were repeated a minimum of three times. Statistical comparisons were made using Student's t-test. $\mathrm{P}<0.05$ was considered to indicate a statistically significant difference. Error bars represent the mean \pm standard deviation unless otherwise stated.

\section{Results}

Inhibition of autophagy or ER stress sensitizes MCF-7 cells to $M G-132$. To examine the effect of inhibiting autophagy or ER stress following inhibition of the proteasome on cell viability, the MCF-7 cells were treated with MG-132, MG-132 and 3-MA, or MG-132 and salubrinal for 12, 24 and $48 \mathrm{~h}$. Cell viability was then determined using an MTT assay. Compared with the untreated control cells, MG-132 marginally inhibited cell viability. Notably, inhibition of either autophagy with 3-MA or ER stress by salubrinal enhanced the loss of cell viability by MG-132 (Fig. 1A). Cell apoptosis was detected using annexin V-FITC and PI staining. Compared with the untreated control, MG-132 induced apoptosis (Fig. 1B and C). Co-treatment of MG-132 with either 3-MA (Fig. 1D) or salubrinal (Fig. 1E) resulted in enhanced cell apoptosis, compared with that in the cells treated with MG-132 alone. In addition, the percentage of MCF-7 cells in the $\mathrm{G}_{2}$ phase was increased to $22.40,24.80$ and $25.76 \%$ by MG-132, MG-132+3-MA, and MG-132+salubrinal, respectively.

Inhibition of ER stress prevents the induction of autophagy by MG-132. To determine the effects of MG-132, 3-MA, and salubrinal on autophagy, the protein levels of LC3, a marker of autophagy, were assessed using western blotting. LC3 has a cytosolic form (LC3-I; 18-kDa) and a lipidated form (LC3-II; $16 \mathrm{kDa}$, and the conversion of LC3-I to LC3-II indicates the induction of autophagy (27). As shown in Fig. 2, the expression of LC3-I was reduced, and the expression of LC3-II was increased in the MG-132-treated cells. The expression of LC3-I was increased and the conversion of LC3-I to LC3-II was reduced following the addition of 3-MA, which occurred in a dose-dependent manner. Similarly, in the cells treated with MG-132 and salubrinal (10 and $20 \mu \mathrm{mol} / \mathrm{l})$, the expression of LC3-I was increased and the conversion of LC3-I to LC3-II was reduced.

Inhibition of autophagy or ER stress potentiates MG-132-induced apoptosis in MCF-7 cells. To investigate whether MG-132-induced apoptosis can be upregulated by inhibiting autophagy or ER stress, the MCF-7 cells were treated with MG-132 in the presence or absence of 3-MA or salubrinal for $48 \mathrm{~h}$, following which the protein expression levels of Bax, Bcl-2 and caspase-3 were determined. As shown in Fig. 3, the protein expression of anti-apoptotic Bcl-2 was reduced in the MG-132-treated cells, and was downregulated further following co-treatment with 3-MA or salubrinal. The expression levels of the apoptotic proteins, Bax and caspase-3, were increased in the MG-132-treated cells, compared with the control cells, and the levels were further upregulated following co-treatment with 3-MA or salubrinal.

Salubrinal inhibits ER stress induced by MG-132. Grp-78 and GADD153 proteins are associated with ER stress, and caspase-12 is associated with ER stress-induced apoptosis $(19,28,29)$. To determine the effect of ER stress on MCF-7 cells following treatment with MG-132, the MCF-7 cells were treated with MG-132 in the presence or absence of salubrinal for $48 \mathrm{~h}$, and the mRNA and protein expression levels of Grp-78, GADD153 and caspase-12 were determined using 
A

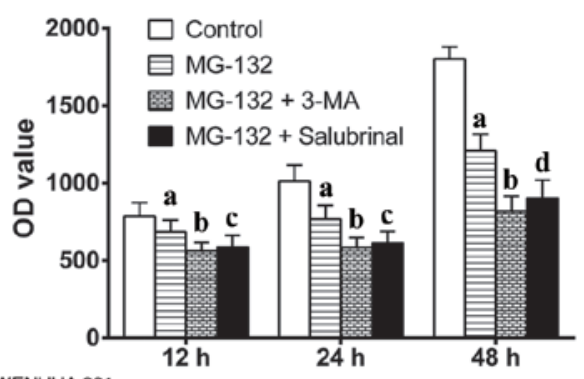

B
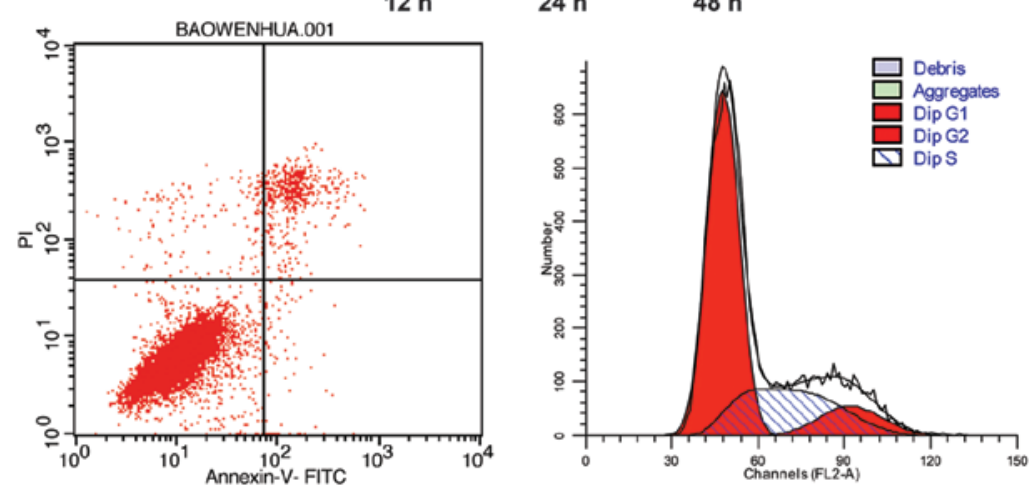

$\mathbf{C}$
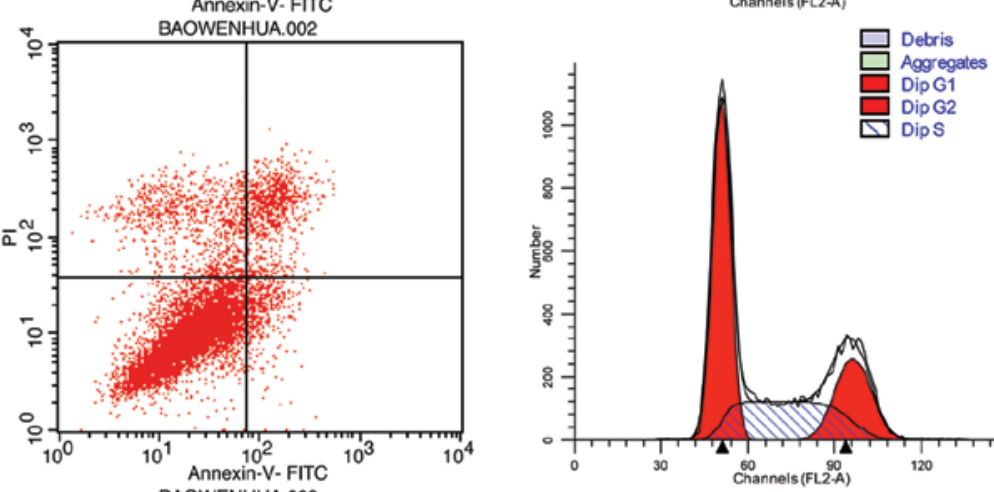

D
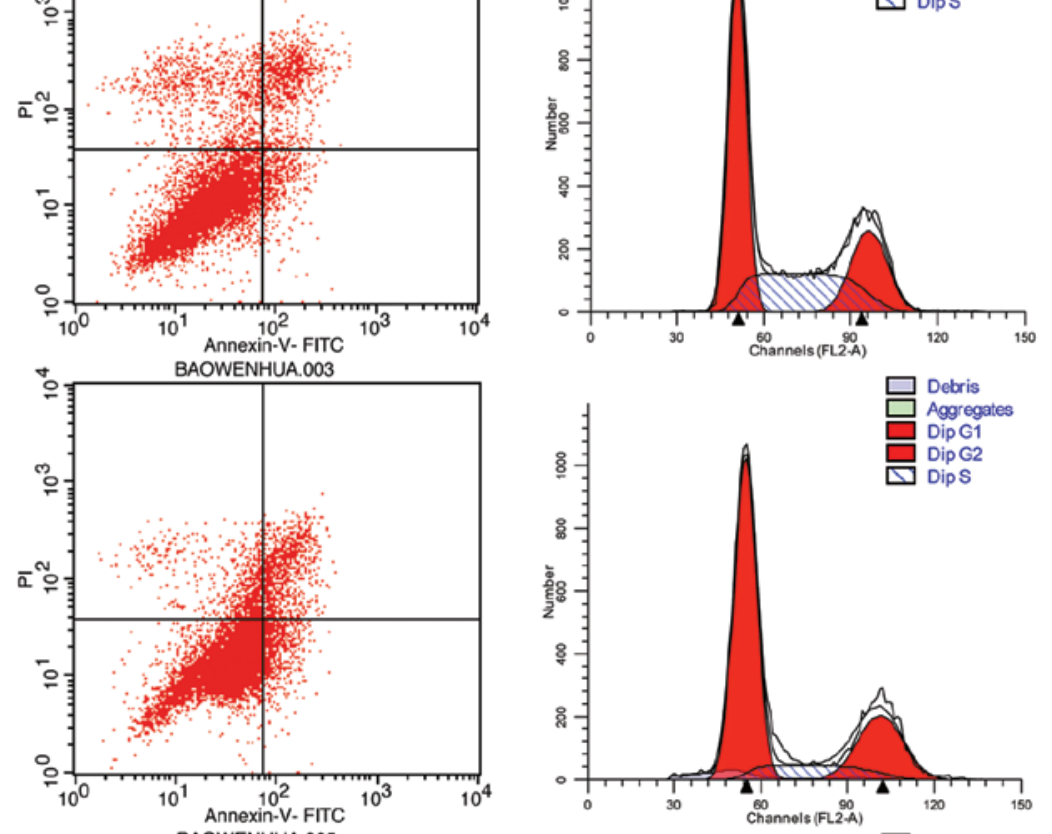

$\mathbf{E}$
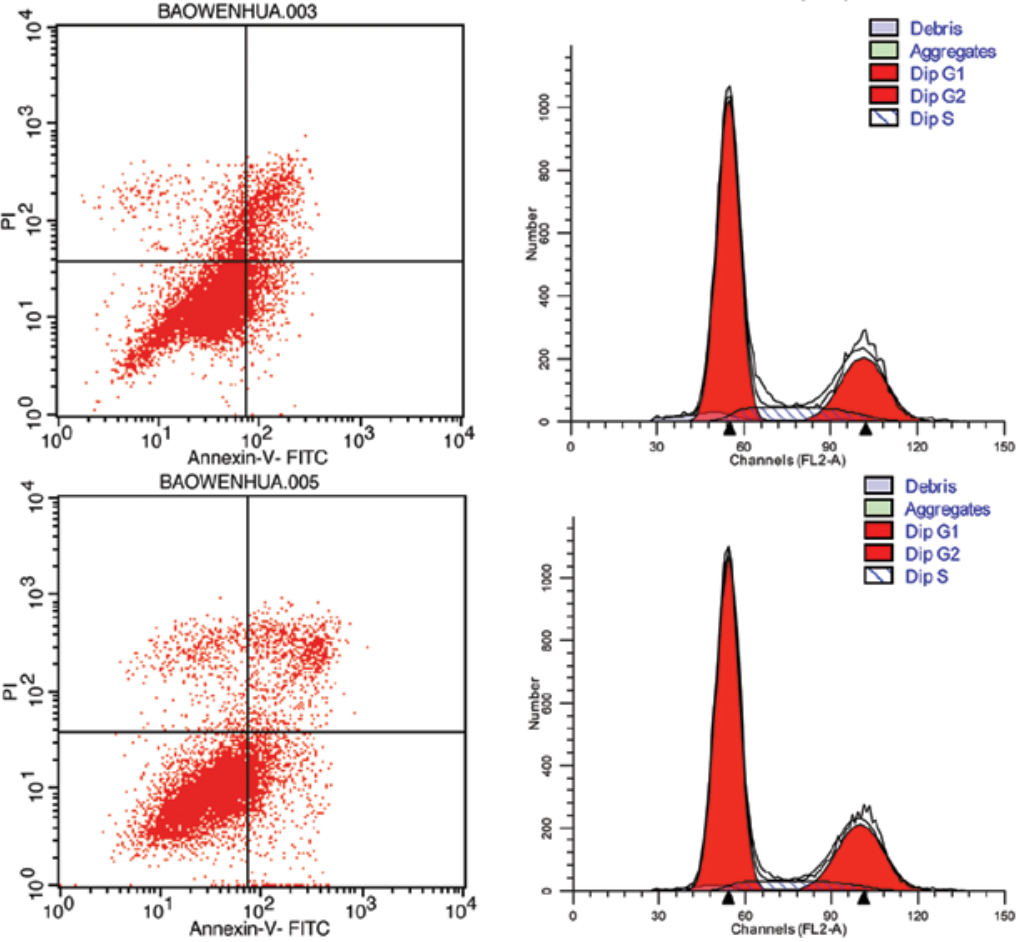

Figure 1. 3-MA and salubrinal enhance cell death induced by MG-132 in MCF-7 cells. The MCF-7 cells were treated with MG-132 $(2.5 \mu \mathrm{mol} / \mathrm{l})$, MG-132+3-MA (1 mmol/l) or MG-132+salubrinal $(10 \mu \mathrm{mol} / \mathrm{l})$ for 12,24 and $48 \mathrm{~h}$. (A) Cell proliferation was determined using a 3-(4,5-dimethylthiazol-2-yl)-2,5-diphenyltetrazolium bromide assay. Apoptosis and the cell cycle were determined using flow cytometry following annexin V-FITC and PI staining. (B) Control; (C) MG-132 (2.5 $\mu \mathrm{mol} / \mathrm{l})$; (D) MG-132 (2.5 $\mu \mathrm{mol} / \mathrm{l})+3$-MA (1 mmol/l); (E) MG-132 (2.5 $\mu \mathrm{mol} / \mathrm{l})+\mathrm{salubrinal}$ $(10 \mu \mathrm{mol} / \mathrm{l})$. Error bars represent the mean \pm standard deviation; ${ }^{\mathrm{a}} \mathrm{P}<0.05$, vs. control group at each time point; ${ }^{\mathrm{b}} \mathrm{P}<0.05$, vs. MG-132 group at each time point; ${ }^{\mathrm{c}} \mathrm{P}<0.05$, vs. MG-132 group at $24 \mathrm{~h}$ and $48 \mathrm{~h} ;{ }^{\mathrm{d}} \mathrm{P}<0.01$, vs. MG-132 group at $48 \mathrm{~h} .3$-MA, 3-methyladenine; FITC, fluorescein isothiocyanate; PI, propidium iodide; OD, optical density. 

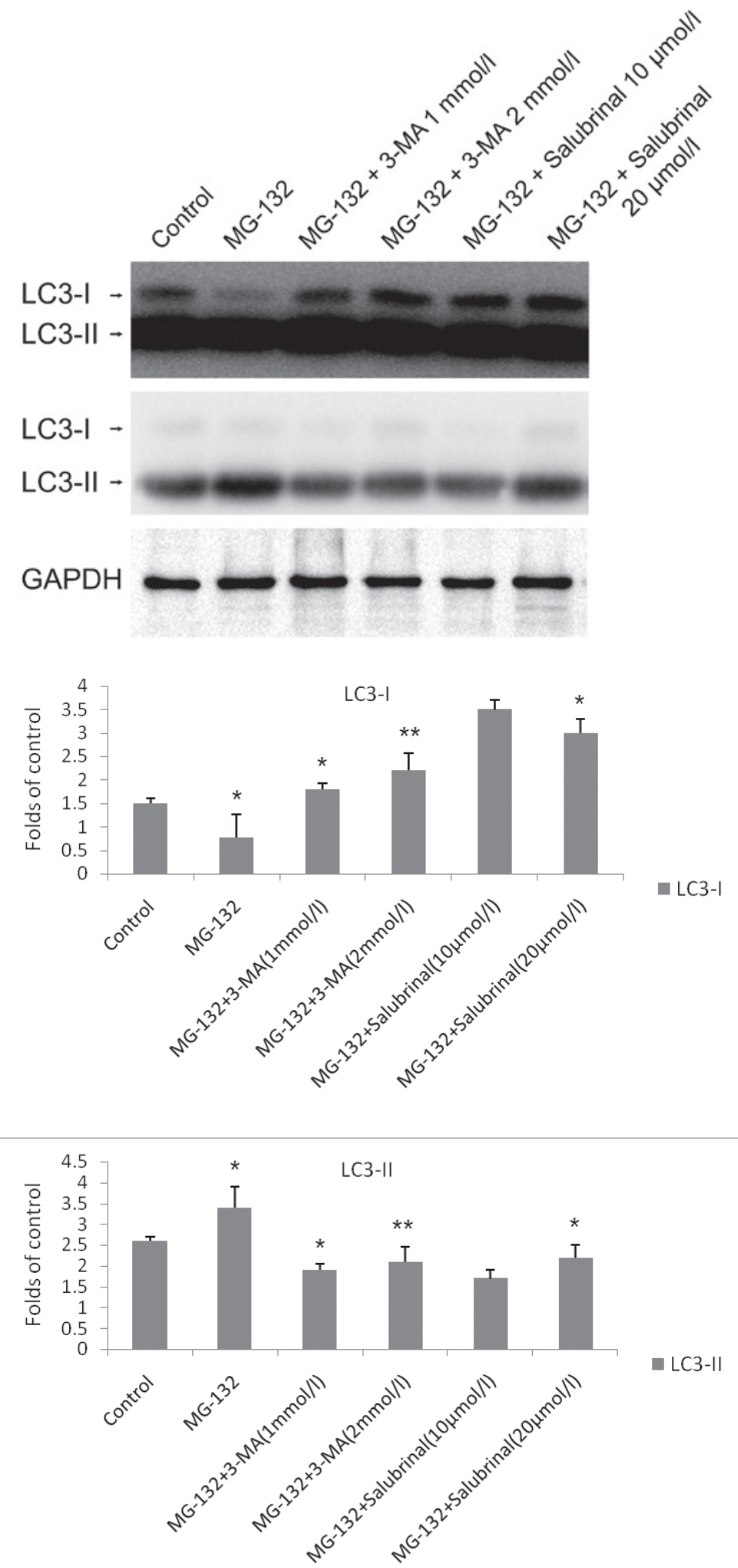

Figure 2. 3-MA and salubrinal reverse the conversion of LC3-I to LC3-II following treatment of MCF-7 cells with MG-132. The MCF-7 cells were treated with MG-132, MG-132+3-MA (1 or $2 \mathrm{mmol} / \mathrm{l})$ or MG-132+salubrinal (10 or $20 \mu \mathrm{mol} / \mathrm{l})$ for $48 \mathrm{~h}$. The total proteins were probed for LC3 and GAPDH (loading control) using western blotting. " $\mathrm{P}<0.05,{ }^{* *} \mathrm{P}<0.01$, compared with the control. 3-MA, 3-methyladenine; GAPDH, glyceraldehyde 3-phosphate; LC3, microtubule-associated protein 1 light chain 3.

RT-qPCR and western blotting, respectively. MG-132 markedly increased the mRNA levels of Grp-78, GADD153 and caspase-12. However, salubrinal inhibited the mRNA levels of Grp-78, GADD153 and caspase-12, in a dose-dependent manner (Fig. 4A). As expected, MG-132 increased the protein expression levels of Grp-78, GADD153 and caspase-12, the effect of which was also eliminated by salubrinal in a dose-dependent manner (Fig. 4B). 

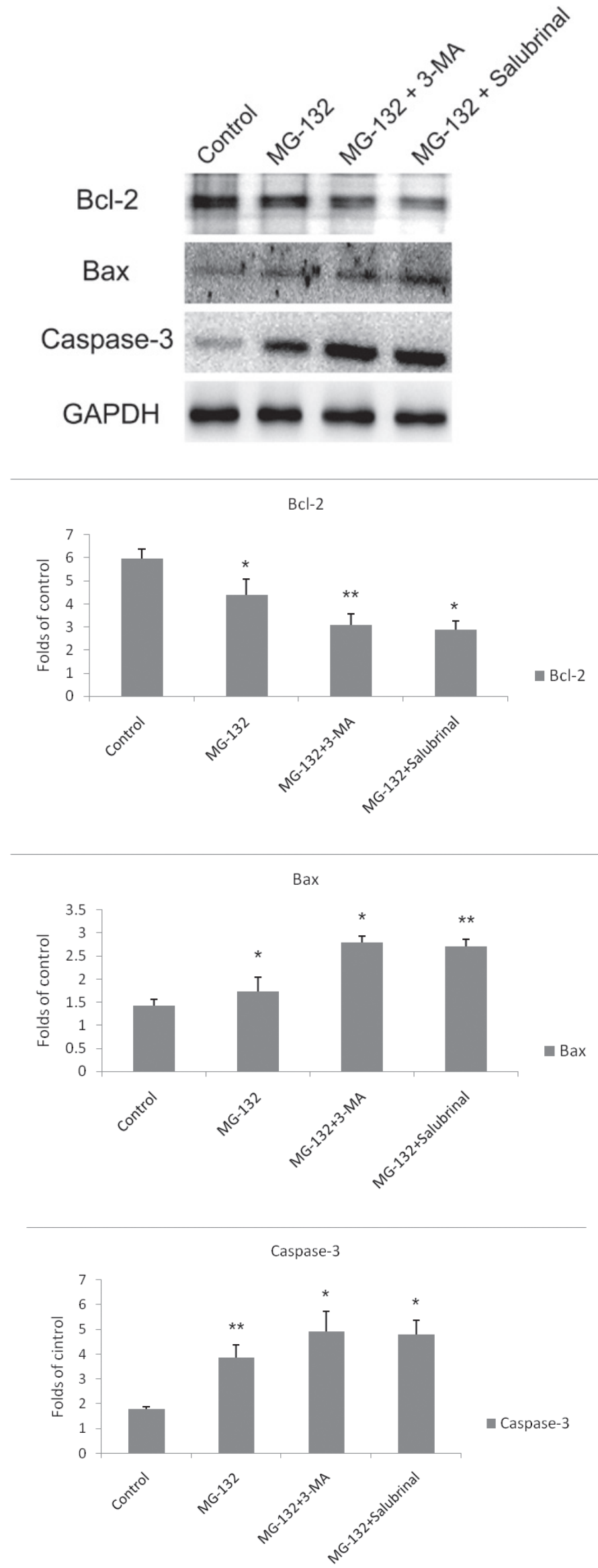

Figure 3. MG-132-induced apoptosis is potentiated by 3-MA and salubrinal. The MCF-7 cells were treated with MG-132 (2.5 $\mu \mathrm{mol} / \mathrm{l})$ in the presence or absence of 3-MA $(1 \mathrm{mmol} / \mathrm{l})$ or salubrinal $(10 \mu \mathrm{mol} / \mathrm{l})$ for $48 \mathrm{~h}$. The protein levels of Bax, Bcl-2 and caspase-3 were determined using western blotting. GAPDH served as a loading control. ${ }^{*} \mathrm{P}<0.05,{ }^{* * *} \mathrm{P}<0.01$, compared with the control. 3-MA, 3-methyladenine; Bcl-2, B cell lymphoma 2; Bax, Bcl-2-associated X protein. 

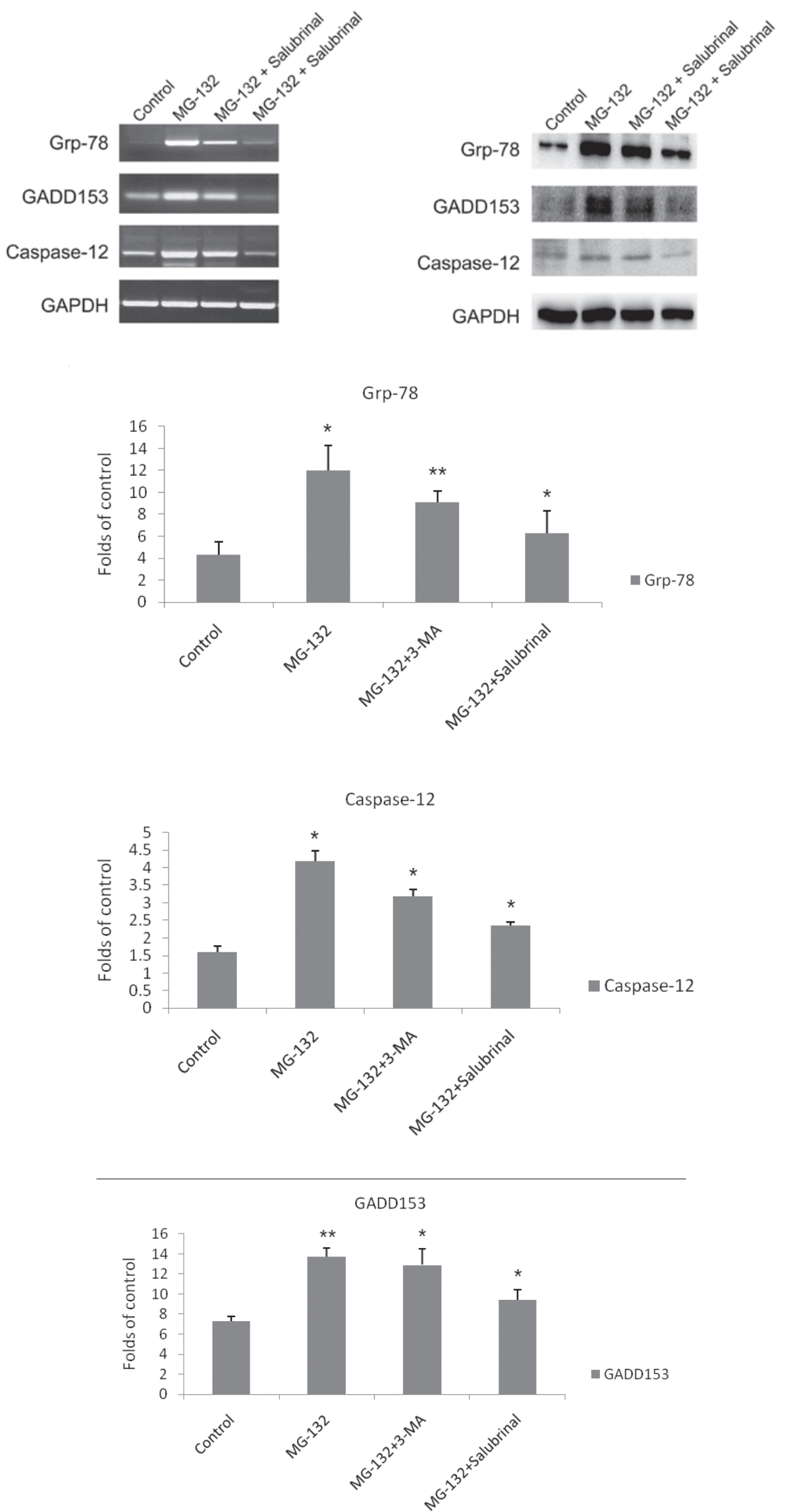

Figure 4. Salubrinal inhibits endoplasmic reticulum stress in MCF-7 cells. MCF-7 cells were treated with MG-132 in the presence or absence of salubrinal ( 10 or $20 \mathrm{mmol} / \mathrm{l}$ ) for $48 \mathrm{~h}$. The mRNA levels of Grp-78, GADD153 and caspase-12 were determined using reverse transcription-quantitative polymerase chain reaction analysis and western blotting. ${ }^{*} \mathrm{P}<0.05,{ }^{* *} \mathrm{P}<0.01$, compared with the control. Grp-78, glucose-regulated protein 78; GADD152, growth arrest and DNA damage induced gene-153. 


\section{Discussion}

In the present study, it was demonstrated that inhibition of the proteasome by MG132 resulted in ER stress, and inhibiting autophagy and ER stress following MG-132 treatment inhibited cell viability. The inhibitory effect of 3-MA was observed to be more effective than that of salubrinal. In addition, the inhibition of ER stress prevented the induction of autophagy by MG-132, suggesting that MG-132-induced autophagy may be associated with ER stress. Notably, the inhibition of autophagy or ER stress potentiated MG-132-induced apoptosis in the MCF-7 cells. The present study demonstrated that ER stress may contribute to the induction of autophagy by proteasome inhibition, and suggested that inhibitors of ER stress and autophagy may be promising in the development of novel combinatorial targeted cancer therapies using proteasome inhibitors.

Autophagy can induce cancer cell death through an apoptosis-dependent or an apoptosis-independent cascade (30), and can promote tumor cell survival by degrading misfolded proteins and damaged organelles $(31,32)$. Previous studies have suggested that the inhibition of autophagy may lead to apoptosis of tumor cells, which is associated with the release of cytochrome $c$, the activation of caspase-3 and poly ADP ribose polymerase, the phosphorylation of p53 and downregulation of the anti-apoptotic Bcl-2 protein (33-35). It was previously reported that MG-132-induced autophagy has a protective role in breast cancer cells, whereas the autophagy inhibitor, 3-MA, can enhance the cell death-inducing effect of MG-132 in MCF-7 cells (9). In agreement, the present study found that the inhibition of autophagy sensitized the MCF-7 cells to MG-132 treatment. However, the mechanism by which inhibition of the proteasome leads to the autophagy of tumor cells remains to be fully elucidated.

ER stress is a highly conserved signal, which has been investigated in several different types of cell and tissue (36). Mild ER stress results in an adaptive response by autophagy to avoid cell death, however, excessive ER stress can lead to cell death (37). ER stress resulting from abnormal protein aggregation in the ER can activate the PERK pathway, which promotes the phosphorylation of eIF $2 \alpha$ to induce the conversion of LC3-I to LC3-II (38). The results of the present study indicated that ER stress inhibited MG-132-induced apoptosis in the MCF-7 cells. This supports the finding of a previous observation that the accumulation of misfolded proteins, resulting from inhibition of the UPP, trigger ER stress, which in turn induces autophagy (39). Despite accumulating evidence demonstrating that inhibition of the proteasome activates ER stress, others have reoirted that excessive stress in the ER increases ATF4 translation by the PERK pathway. This results in a mitogen-activated protein kinase kinase kinase activation cascade, via the inositol-requiring enzyme 1 pathway, leading to apoptosis (19). The results of the present study indicated that salubrinal increased apoptosis, decreased the expression of ER stress-associated protein, enhanced MG-132-induced cell death and increased the number of MCF-7 cells in the $\mathrm{G}_{2} / \mathrm{M}$ phase. These results indicated that salubrinal inhibited the activation of autophagy by inhibiting ER stress, thus indirectly enhancing the cell death-inducing effect of the MG-132 proteasome inhibitor.
In conclusion, the results of the present study suggested that the proteasome inhibitor, MG-132, induced autophagy via the ER stress pathway, which ultimately resulted in apoptosis of the MCF-7 cells. In addition, the inhibition of autophagy and ER stress enhanced cell death and inhibited cell proliferation. These findings may provide a theoretical basis for the application of inhibitors of ER stress and autophagy in combination with proteasome inhibitors for the development of novel combinatorial treatment strategies in targeted cancer therapy.

\section{Acknowledgements}

The presentstudy wasfunded by grants from the National Natural Science Foundation of China (grant. no. 20130101150JC).

\section{References}

1. Rubinsztein DC: The roles of intracellular protein-degradation pathways in neurodegeneration. Nature 443: 780-786, 2006.

2. Hershko A: The ubiquitin system for protein degradation and some of its roles in the control of the cell division cycle. Cell Death Differ 12: 1191-1197, 2005.

3. Momose I, Iijima M, Kawada M and Ikeda D: A new proteasome inhibitor, TP-110, induces apoptosis in human prostate cancer PC-3 cells. Biosci Biotechnol Biochem 71: 1036-1043, 2007.

4. Yang H, Landis-Piwowar KR, Chen D, Milacic V and Dou QP: Natural compounds with proteasome inhibitory activity for cancer prevention and treatment. Curr Protein Pept Sci 9: 227-239, 2008

5. Fan WH, Hou Y, Meng FK, Wang XF, Luo YN and Ge PF: Proteasome inhibitor MG-132 induces C6 glioma cell apoptosis via oxidative stress. Acta Pharmacol Sin 32: 619-625, 2011.

6. Testa U: Proteasome inhibitors in cancer therapy. Curr Drug Targets 10: 968-981, 2009.

7. Levine B and Kroemer G: Autophagy in the pathogenesis of disease. Cell 132: 27-42, 2008.

8. Shintani T and Klionsky DJ: Autophagy in health and disease: A double-edged sword. Science 306: 990-995, 2004.

9. Ge PF, Zhang JZ, Wang XF, Meng FK, Li WC, Luan YX, Ling F and Luo YN: Inhibition of autophagy induced by proteasome inhibition increases cell death in human SHG-44 glioma cells. Acta Pharmacol Sin 30: 1046-1052, 2009

10. Zhu K, Dunner K Jr and McConkey DJ: Proteasome inhibitors activate autophagy as a cytoprotective response in human prostate cancer cells. Oncogene 29: 451-462, 2010.

11. Nishikawa T, Tsuno NH, Okaji Y, Shuno Y, Sasaki K, Hongo K, Sunami E, Kitayama J, Takahashi K and Nagawa H: Inhibition of autophagy potentiates sulforaphane-induced apoptosis in human colon cancer cells. Ann Surg Oncol 17: 592-602, 2010.

12. Davids LM, Kleemann B, Cooper S and Kidson SH: Melanomas display increased cytoprotection to hypericin-mediated cytotoxicity through the induction of autophagy. Cell Biol Int 33: 1065-1072, 2009.

13. Katayama M, Kawaguchi T, Berger MS and Pieper RO: DNA damaging agent-induced autophagy produces a cytoprotective adenosine triphosphate surge in malignant glioma cells. Cell Death Differ 14: 548-558, 2007.

14. Li J, Qin Z and Liang Z: The prosurvival role of autophagy in Resveratrol-induced cytotoxicity in human U251 glioma cells. BMC Cancer 9: 215, 2009.

15. Apel A, Herr I, Schwarz HP, Rodemann HP and Mayer A: Blocked autophagy sensitizes resistant carcinoma cells to radiation therapy. Cancer Res 68: 1485-1494, 2008.

16. Kim KW, Hwang M, Moretti L, Jaboin JJ, Cha YI and Lu B: Autophagy upregulation by inhibitors of caspase-3 and mTOR enhances radiotherapy in a mouse model of lung cancer. Autophagy 4: 659-668, 2008.

17. Vazquez-Martin A, Oliveras-Ferraros C and Menendez JA: Autophagy facilitates the development of breast cancer resistance to the anti-HER2 monoclonal antibody trastuzumab. PloS One 4: e6251, 2009.

18. Song J, Qu Z, Guo X, Zhao Q, Zhao X, Gao L, Sun K, Shen F, Wu M and Wei L: Hypoxia-induced autophagy contributes to the chemoresistance of hepatocellular carcinoma cells. Autophagy 5: 1131-1144, 2009. 
19. Moretti L, Cha YI, Niermann KJ and Lu B: Switch between apoptosis and autophagy: Radiation-induced endoplasmic reticulum stress? Cell Cycle 6: 793-798, 2007.

20. DeGracia DJ and Montie HL: Cerebral ischemia and the unfolded protein response. J Neurochem 91: 1-8, 2004.

21. Kapoor A and Sanyal AJ: Endoplasmic reticulum stress and the unfolded protein response. Clin Liver Dis 13: 581-590, 2009.

22. Fujita E, Kouroku Y, Isoai A, Kumagai H, Misutani A, Matsuda C, Hayashi YK and Momoi T: Two endoplasmic reticulum-associated degradation (ERAD) systems for the novel variant of the mutant dysferlin: Ubiquitin/proteasome ERAD(I) and autophagy/lysosome ERAD(II). Hum Mol Genet 16 618-629, 2007.

23. Yorimitsu T, Nair U, Yang Z and Klionsky DJ: Endoplasmic reticulum stress triggers autophagy. J Biol Chem 281: 30299-30304, 2006.

24. Gavilán MP, Pintado C, Gavilán E, Jiménez S, Ríos RM, Vitorica J, Castaño A and Ruano D: Dysfunction of the unfolded protein response increases neurodegeneration in aged rat hippocampus following proteasome inhibition. Aging Cell 8: 654-665, 2009.

25. Younce CW and Kolattukudy PE: MCP-1 causes cardiomyoblast death via autophagy resulting from ER stress caused by oxidative stress generated by inducing a novel zinc-finger protein, MCPIP. Biochem J 426: 43-53, 2010.

26. Zhou F, van Laar T, Huang H and Zhang L: APP and APLP1 are degraded through autophagy in response to proteasome inhibition in neuronal cells. Protein Cell 2: 377-383, 2011.

27. Tanida I, Ueno T and Kominami E: LC3 conjugation system in mammalian autophagy. Int J Biochem Cell Biol 36: 2503-2318, 2004.

28. Heath-Engel HM, Chang NC and Shore GC: The endoplasmic reticulum in apoptosis and autophagy: Role of the BCL-2 protein family. Oncogene 27: 6419-6433, 2008.

29. Oyadomari S and Mori M: Roles of CHOP/GADDI53 in endoplasmic reticulum stress. Cell Death Differ 11: 381-389, 2004.
30. Yu L, Alva A, Su H, Dutt P, Freundt E, Welsh S, Baehrecke EH and Lenardo MJ: Regulation of an ATG7-beclin 1 program of autophagic cell death by caspase-8. Science 304: 1500-1502, 2004.

31. Cuervo AM, Stefanis L, Fredenburg R, Lansbury PT and Sulzer D: Impaired degradation of mutant alpha-synuclein by chaperone-mediated autophagy. Science 305: 1292-1295, 2004.

32. Rubinsztein DC, DiFiglia M, Heintz N, Dutt P, Freundt E, Welsh S, Baehrecke EH and Lenardo MJ: Autophagy and its possible roles in nervous system diseases, damage and repair. Autophagy 1: 11-22, 2005.

33. Li J, Hou N, Faried A, Tsutsumi S, Takeuchi T and Kuwano H: Inhibition of autophagy by 3-MA enhances the effect of 5-FU-induced apoptosis in colon cancer cells. Ann Surg Oncol 16: 761-771, 2009.

34. Huang S and Sinicrope FA: Celecoxib-induced apoptosis is enhanced by ABT-737 and by inhibition of autophagy in human colorectal cancer cells. Autophagy 6: 256-269,2010.

35. Walls KC, Ghosh AP, Franklin AV, Klocke BJ, Ballestas M, Shacka JJ, Zhang J and Roth KA: Lysosome dysfunction triggers Atg7-dependent neural apoptosis. J Biol Chem 285: 10497-10507, 2010.

36. McMillan DR, Gething MJ and Sambrook J: The cellular response to unfolded proteins: Intercompartmental signaling. Curr Opin Biotechnol 5: 540-545, 1994.

37. Gao B, Zhang XY, Han R, Zhang TT, Chen C, Qin ZH and Sheng R: The endoplasmic reticulum stress inhibitor salubrinal inhibits the activation of autophagy and neuroprotection induced by brain ischemic preconditioning. Acta Pharmacol Sin 34: 657-666, 2013

38. Hoyer-Hansen $M$ and Jäättelä $M$ : Connecting endoplasmic reticulum stress to autophagy by unfolded protein response and calcium. Cell Death Differ 14: 1576-1582, 2007.

39. Ding WX, Ni HM, Gao W, Yoshimori T, Stolz DB, Ron D and Yin XM: Linking of autophagy to ubiquitin-proteasome system is important for the regulation of endoplasmic reticulum stress and cell viability. Am J Pathol 171: 513-524, 2007. 